\title{
Hacia un constructivismo realista: de la naturaleza al medio ambiente
}

\author{
Towards a realistic constructivism. \\ From nature to the environment
}

\author{
ManUel ARIAS MaldonAdo
}

Universidad de Málaga

RESUMEN. Si hay un campo en el que tiene importancia el debate acerca de la relación de la sociedad con la naturaleza, es la filosofía y sociología medioambientales. Es un debate dominado por el enfrentamiento entre realismo y constructivismo: entre quienes sostienen que la naturaleza es una entidad independiente de la sociedad y quienes alegan que la naturaleza es una construcción social. Es habitual que esta querella se resuelva mediante la afirmación de que la naturaleza existe, pero sólo la conocemos mediadamente. Sin embargo, es hora de defender una versión del constructivismo que preste la debida atención a la dimensión material de la relación socionatural. La sociedad nunca ha dejado de intervenir en la naturaleza y el resultado final de ese proceso histórico es, de hecho, la transformación de la sociedad en medio ambiente humano. Sólo un constructivismo realista permite poner de manifiesto este rasgo decisivo de la interacción socionatural.

Palabras clave: Realismo, sostenibilidad, límites naturales, valor intrínseco.

\section{Introducción}

Si la disputa sobre la capacidad humana para conocer la realidad ha acompañado a la historia misma de la filosofía, no es de extrañar que su importancia se acre-
Abstract. The relationship between society and nature has an outstanding importance in the fields of environmental philosophy and sociology. It is dominated by the opposition between realism and constructivism, i.e.: between those who argue that nature is an entity independent of society and those who respond that nature is a social construction. Such conflict is usually solved accepting that nature exists but our knowledge of it can only be socially mediated. However, a new version of constructivism is to be defended, one which pays enough attention to the material dimension of society-nature's interaction. Society has always intervened upon nature and the final outcome of such historical process is but the transformation of nature into human environment. A realistic constructivism allows us to highlight that decisive feature of socio-natural interaction.

Key words: Realism, sustainability, natural limits, intrinsic value.

ciente contemporáneamente allí donde la reflexión se ocupa de la relación directa de la sociedad con esa realidad: en la filosofía y sociología medioambientales. No en vano, el debate en torno a la naturaleza de la naturaleza adquiere una relevancia 
decisiva cuando se trata de tomar decisiones orientadas a la consecución de una sociedad sostenible. La querella filosófica es aquí determinante para la decisión política. Sucede que aquel debate ha estado marcado por una oposición - entre realismo y constructivismo - que ha llegado el momento de revisar. Y de hacerlo a la vista de su insuficiencia para dar cuenta de lo que debería ser el punto de partida de nuestra discusión sobre la sostenibilidad: la transformación de la naturaleza en medio ambiente. Se trata, en fin, de dar a la construcción social de la naturaleza un giro realista.

Enraizados en distintas teorías del conocimiento, realismo y construccionismo defienden dos concepciones diferentes de la naturaleza y de nuestra capacidad para acceder a ella. Para el realismo, la naturaleza es una entidad objetivable, autónoma e independiente del hombre: una realidad cognoscible situada más allá de la esfera social. Para el constructivismo, en cambio, la naturaleza no es una entidad independiente, sino el producto de una construcción social a través del lenguaje y la cultura; no podemos conocerla sino a través de la sociedad misma. $\mathrm{Si}$ el constructivismo radical niega a la naturaleza una ontología independiente, el moderado sostiene que no debemos preocuparnos por esa ontología, dado que no podemos acceder a ella. Naturalmente, cada una de estas teorías produce una distinta comprensión de la relación socionatural; en consecuencia, sirven para sostener distintas orientaciones morales y modelos dispares de sostenibilidad.

Sin ir más lejos, una parte de la teoría sociológica medioambiental vino a reprochar al campo constructivista la ausencia de un compromiso moral suficiente con la defensa de la naturaleza (Dunlap y Catton, 1994: 20; Benton, 1994: 174; Martell, 1994: 74). La idea subyacente es que quien se desentiende de la realidad natural adoptando una posición constructivista abraza una neutralidad epistemológica incompatible con una posición moral. El constructivismo sería toda una declaración de guerra contra la naturaleza (Lease, 1995: 4). Más recientemente, este argumento ha encontrado eco en la afirmación de que el reconocimiento de la dimensión social de la naturaleza ha obstaculizado decisivamente el desarrollo de un ecologismo transformador, al relativizar la incompatibilidad del actual modelo social y una hipotética sociedad sostenible (Blühdorn y Welsh, 2007: 192). De manera que es ya un lugar común afirmar que el constructivismo es una amenaza para el pensamiento verde y la protección misma de la naturaleza (Rogers, 2009: 1; Plumwood, 2005: 27). Todo lo cual demuestra la importancia de un debate que está lejos de ser mera charlatanería filosófica. A fin de cuentas, si el mundo natural no posee un valor independiente del hombre, el ecologismo político no puede razonar como si lo tuviera; y viceversa. Que la naturaleza esté ahí fuera o se halle aquí dentro tiene una importancia formidable.

Este trabajo defenderá la necesidad de reformular la oposición entre realismo y constructivismo, a fin de poder explicar plausiblemente el estado de las relaciones socionaturales. Es necesario propiciar un giro realista en el constructivismo, para combinar las indudables virtudes de éste con la insoslayable dimensión material de la interacción entre humanidad y naturaleza. No sólo construimos el concepto de naturaleza, sino que la realidad natural misma es en gran medida producto de la construcción social. Si, en el primer caso, nuestro concepto de naturaleza parte de una realidad observable, en el segundo el trabajo humano sobre el medio se efectúa también sobre una realidad material. La construcción social de la naturaleza no equivale a una fabulación, sino al resulta- 
do de un proceso relacional de co-evolución que lleva miles de años en marcha. $\mathrm{Su}$ resultado final es la transformación de la sociedad en medio ambiente humano.

\section{La construcción social de la naturaleza}

La explicación constructivista de la naturaleza es una aplicación a ésta del más amplio paradigma del constructivismo social. Sus raíces se hallan en la sociología del conocimiento marxista y su influencia, sobre todo a partir del texto seminal de Berger y Luckmann (1984), no ha dejado de crecer, algo especialmente visible en la psicología y en el desarrollo de la teoría de los marcos de conocimiento. Tanto el llamado giro lingüístico como la defensa posmoderna del relativismo cultural han contribuido a su generalización.

Su punto de partida es la imposibilidad de aprehender la realidad directa y objetivamente. Ésta es siempre capturada, clasificada y experimentada a través de categorías sociales, cuya importancia mediadora es tal que terminan por constituir esa misma realidad, revelada así sobre todo como construcción social. Más que la realidad, por tanto, existen distintas realidades, que son relativas al punto de vista lingüístico o cultural desde el que se las formula. Es precisamente esto lo que pasan por alto las posturas objetivistas que proclaman nuestra capacidad para acceder a la realidad, a saber, que ésta nunca nos llega tal como es, sino social y culturalmente filtrada. El constructivismo trata de «aislar, analizar y explicar los sutiles mecanismos (y hechizos) mediante los cuales cada sociedad o cultura construye su imagen del mundo y de sí misma» (Castro Nogueira et alii, 2005: 567). No puede sorprender que el lenguaje cobre una decisiva importancia en este análisis, por tratarse de la primera instancia de mediación entre el hombre y la rea- lidad; el discurso se convierte así en un factor principal en la creación social de la realidad. Y en consecuencia, toda forma de naturalización de lo social es considerada como un intento de legitimación de convenciones sociales que tienen un origen cultural y una función ideológica susceptibles de discernimiento: todo está construido, todo es lenguaje.

Pues bien, si la realidad en su conjunto es una construcción social, la naturaleza también lo es. Tampoco el mundo no humano se sustrae a la mediación de la sociedad: la verdad acerca de la naturaleza es su verdad social. No es una esencia atemporal, ni podemos pensar en ella como algo separado de la existencia humana. Eso significa, igualmente, que no podemos hablar de una naturaleza universal, ya que distintos contextos culturales, posiciones sociales y momentos históricos producirán distintas visiones de la naturaleza (cfr. Macnaghten y Urry, 1998). En lugar de una única naturaleza singular, coexisten diversas naturalezas, constituidas mediante diferentes procesos socioculturales, de los que no pueden desligarse. De ahí que conceptos como los de naturaleza o mundo no humano carezcan de significados fijos y sean, por el contrario, socialmente discutidos.

No obstante, la visión constructivista de la naturaleza no es una mera aplicación del constructivismo social a la esfera del mundo natural, sino que se articula de un modo algo más complejo. Sobre todo, porque está relacionado directamente con la emergencia del naturalismo filosófico y la consiguiente oposición entre naturaleza y cultura. Son los padres fundadores de la sociología los que, como reacción al predominio del pensamiento biologicista que sigue al advenimiento del darwinismo, hacen una doble afirmación: que lo social goza de autonomía frente a lo natural y que el hombre posee una excepcionalidad irreductible a la suma de sus con- 
dicionantes biológicos. Y ello porque del hecho de que la especie humana sea el producto de procesos naturales no se sigue que todo lo que hacemos sea natural (Moriarty, 2007: 233). Es decir, que ni la naturaleza existe con independencia del hombre, ni el hombre es sólo una parte de ella; una proclamación que está en la raíz de la visión constructivista. Se trata de una reacción contra las explicaciones naturalistas que dan cuenta de la evolución social como continuación de procesos naturales: la naturaleza pasa ahora a considerarse algo no dado objetivamente, sino simbólicamente constituido. Y la constitución natural de la sociedad se ve así reemplazada por la construcción social de la naturaleza.

\section{Constructivismo radical versus constructivismo moderado}

Que puedan señalarse algunos rasgos comunes no implica, empero, que exista una sola forma de constructivismo medioambiental. Por el contrario, suele distinguirse entre dos variantes - radical y moderada- del mismo. La diferencia entre ambas estriba en el grado de realidad independiente que admiten fuera de la esfera del conocimiento humano, o dicho de otra manera, en el predicado de la construcción: según éste sea el objeto de nuestro conocimiento - la realidad natural- o el conocimiento mismo. Pero veámoslo con mayor detalle.

De una parte, el constructivismo ontológico o radical atañe a la esencia misma de la naturaleza: a su estatuto metafísico. Niega la existencia de independiente de un mundo no humano, porque éste sólo cobra vida en el interior del discurso social. El mundo natural no es más que otra categoría social, un artefacto discursivo sin existencia independiente. Es una variante del antifundacionalismo que apunta hacia la constitución social de la realidad externa, que por tanto no es ex- terna en absoluto. La naturaleza misma es por ello algo inaccesible y sólo cuenta para nosotros como percepción - socialmente mediada- de un mundo ininteligible fuera del lenguaje. En consecuencia, no existe un mundo natural independiente del discurso y la construcción sociales. Para conocer la naturaleza, tenemos que conocer nuestra propia construcción de la naturaleza.

En cambio, el constructivismo epistemológico o moderado circunscribe esa dependencia contextual al conocimiento de la naturaleza. Aunque ésta es una entidad real y objetiva que sí tiene existencia propia, nuestro acceso a ella está inevitablemente sometido a un conjunto de mediaciones y filtros culturales que nos impiden conocerla directamente. El mundo natural no es cognoscible al margen de estas mediaciones sociales, de manera que no puede haber una naturaleza universal, sino divergentes construcciones de la naturaleza determinadas por distintas circunstancias sociohistóricas. Así que llamamos naturaleza a nuestra particular aprehensión del mundo natural realmente existente. En términos kantianos, la naturaleza es el fenómeno que somos capaces de describir con nuestras anteojeras culturalmente específicas; el mundo no humano, el noúmeno que inevitablemente permanece fuera de nuestro alcance cognitivo: el objeto real, el conocimiento es construido.

Quod veritas? Cuando la sociología verde arremete contra el construccionismo, ha solido hacerlo en su versión ontológica o radical (Dickens, 1996: 74; Benton, 1994; 45; Martell, 1994: 131). Y es que la suya es, en principio, una tesis fácilmente refutable. ¡Por muchas maneras que existan de construir culturalmente un animal, ninguno de esos posibles discursos tiene nada que ver con el modo en que el animal está fisicamente constituido! Esto es evidente, pero quizá la pro- 
puesta del constructivista radical no sea tan simple. Su sugerencia es, más bien, que debemos suspender nuestros juicios acerca de la ontología del mundo no humano, porque nuestra percepción de éste depende de nuestras representaciones; representaciones que preceden a nuestra percepción. La idea del animal que contemplamos es el animal. Dado que no podemos estar entonces seguros de que exista una correspondencia entre nuestros juicios sobre la realidad y la realidad misma, tales juicios son estériles (cfr. Smith, 1999). Aún así, es dudoso que semejante enfoque tenga utilidad alguna en el estudio de las relaciones socionaturales, a pesar de que, como veremos, su tesis pueda resultar inesperadamente provechosa en el marco de un constructivismo reformulado.

En realidad, la práctica sociológica apenas conoce ejemplos de aplicación del enfoque radical al estudio de la naturaleza: el constructivismo moderado es dominante (Burnigham y Cooper, 1999: 303). Su propósito general es desentrañar el modo en que la realidad social es construida, prestando atención a los procesos sociales que influyen en la producción de ciencia y conocimiento (Sismondo, 1993). Ted Benton distingue así, a partir del realismo crítico de Roy Baskhar, entre la construcción del conocimiento y el realismo del objeto: los procesos naturales existen al margen del hombre, pero nuestro conocimiento sobre ellos es una construcción social (Benton, 2000). No hay construcción social sin una naturaleza real sobre la que basar esa construcción. La sociología de la ciencia se encargará precisamente de desvelar las razones por las cuales el resultado de ese proceso desemboca en cada caso en un conjunto de creencias y representaciones - en una construcción determinada- y no en otras. Y ello hasta el punto de afirmarse que, si todo conocimiento es sesgado, los sesgos ya no son un criterio para desechar un tipo de conocimiento en favor de otro, de manera que sólo podremos distinguir entre conocimientos, atendiendo a la utilidad pragmática que alcancen sus aplicaciones (Saarikoski, 2007).

Sea como fuere, la conclusión usual en el debate en torno a la oposición entre estas dos formas de constructivismo consiste en la aceptación de la variante epistemológica, que proclama que la naturaleza existe, pero su conocimiento está mediado, en detrimento de la variante ontológica, según la cual no hay mundo exterior, sino sólo discurso. Se alcanza así un razonable término medio, que consiste en el simultáneo reconocimiento de la realidad y de la dependencia sociocultural de nuestro acceso a ella. La naturaleza no es un simple epifenómeno de la sociedad, sino que existe con independencia de nuestra imposibilidad de aprehenderla directamente. Esta conclusión, además, tiene la ventaja de dejar abierta la puerta a otras formas de exploración del orden natural, ya se trate de discursos científicos alternativos o de aprehensiones entre místicas y estéticas, como la defendida por la ecología profunda.

\section{Hacia un constructivismo realista}

Es natural que, reprochándose al constructivismo una presunta incapacidad para sostener un compromiso moral con la defensa del mundo natural, se prefiera una versión moderada del mismo para conjurar esa amenaza. La reformulación de las relaciones socionaturales en busca de la sostenibilidad no puede basarse en una versión ontológica del constructivismo. Sin embargo, hay quienes tampoco pueden aceptar el realismo esencialista habitualmente defendido por los teóricos verdes. Así que para evitar los excesos latentes en esas dos posturas se acude a un constructivismo moderado: la naturaleza 
no es una fabulación lingüística, ni es independiente de la sociedad.

Se hace así necesario trascender el código binario que nos obliga a ver la naturaleza como el conjunto de condiciones materiales de nuestra existencia $o$ como una serie de símbolos culturalmente generados, para aceptarla como ambas cosas. El mundo natural no es una entidad universal, pero tampoco es un simple concepto. No tiene sentido, ciertamente, defender una explicación exclusivamente constructivista de la interacción socionatural, porque si eliminamos uno de los términos de la oposición sociedad-naturaleza estamos privando de sentido a la relación entre ambas. Y es precisamente la falta de atención a la dimensión material de esa relación la que limita considerablemente la capacidad explicativa de esta suerte de constructivismo consensual, así como, dicho sea de paso, de la contraparte realista. Establecer una separación entre la existencia del mundo natural y nuestro conocimiento socialmente generado del mismo supone minusvalorar la importancia formidable de las prácticas humanas, o sea, la interacción - física, material - entre sociedad y naturaleza.

De ahí que, junto a las variantes ontológica y epistemológica de constructivismo, se haga necesario admitir un constructivismo material que imponga un giro realista a este debate y permita dar cuenta de la transformación efectiva de la naturaleza en medio ambiente humano. La construcción tiene aquí lugar en sentido literal: como intervención humana sobre la realidad natural. En esta acepción, la naturaleza es físicamente construida por la humanidad que se la apropia, a través del acto mismo de apropiación mediante el cual se produce la mezcla socionatural. ¿Acaso la transformación social del entorno, la humanización del mundo natural en que se resuelve ese proceso de aprehensión, no es una forma de reproducción de la realidad? Hasta hace poco, podíamos pensar únicamente en avances como el cruce de especies o la clonación, pero la creación de vida artificial y el desarrollo de proyectos que apuntan en la misma dirección por medios distintos a los empleados por el equipo de Craig Venter dejan ya pocas dudas acerca de la capacidad humana - juicios morales aparte- para crear organismos artificiales e intervenir con ello directamente en procesos naturales profundos hasta hace poco tenidos por inaccesibles para el hombre. El hombre no puede crear ex novo procesos naturales, pero sí manipularlos y recombinarlos en un grado que autoriza a hablar, literalmente, de construcción social de la naturaleza.

Tomarse el constructivismo en serio significa entonces otorgar la importancia debida a la extraordinaria interpenetración de sociedad y naturaleza. Y hacerlo para subrayar que, así como el hombre es naturaleza, la naturaleza, debido al proceso de coevolución y recíproca transformación experimentado desde el surgimiento del homo sapiens, es también sociedad. Moscovici se ha referido a una «historia humana de la naturaleza» que ponga fin «a la visión de una naturaleza no humana y de un hombre no natural», ya que naturaleza y sociedad no se excluyen mutuamente, sino que, antes al contrario, «la sociedad es una segunda naturaleza, desde el momento en que separa a la humanidad del reino animal y representa su signo distintivo» (Moscovici, 1975: 27). Sólo una sociedad originada en la naturaleza, pero después separada de ella, permite hablar de interacción entre ella y la naturaleza. Es posible así discriminar entre la condición ontológicamente natural de la sociedad y su desarrollo histórico posterior, en permanente contacto con su base material, pero con relativa independencia de la misma. Sólo 
mediante esa separación puede el hombre dotar de sentido a su presencia en el mundo, adaptarse al mismo mediante la apropiación física y simbólica del entorno, por más que a esa apariencia separada subyazca una esencial unidad ontológica.

Ahora bien, esa misma sociedad que, a través de la cultura y el trabajo, se separa de la naturaleza, es la misma que termina por reintegrarse a ella siguiendo el camino inverso. El intercambio orgánico entre el hombre y su medio físico termina por transformar a la propia naturaleza, poniéndola al servicio del hombre. El medio ambiente humano es el producto final de ese proceso de reconstrucción. No volvemos al punto de partida, como querría el ecologismo político menos realista, sino que sucede lo contrario: si el hombre había pertenecido inicialmente al orden natural, hasta el punto de ser uno con él, ahora ese orden se subsume en el orden social y la propia dicotomía naturaleza-sociedad -inicialmente una invención, después una herramienta- se resuelve en el surgimiento del medio ambiente como categoría que sintetiza a las otras dos. Los mismos procesos naturales dependen ya en gran medida del hombre, como el hombre depende de ellos (cfr. Eder, 1996: 49); y así: «la aceptación del carácter complejo e interactivo del cambio social y medioambiental implica que las distinciones simples entre lo "social" y lo "natural" pronto serán insostenibles») (Redclift, 1999: 68).

En definitiva, la intervención del hombre en la naturaleza es, en el curso de su proceso de apropiación del medio, tan intensa y masiva, que no parece razonable excluir esta dimensión material de un enfoque constructivista. A la realidad ontológica del mundo natural y la cualidad social de nuestro conocimiento del mismo habría que sumar la decisiva aplicación práctica de este conocimiento en aquella realidad; y esa aplicación es tam- bién construcción social de la naturaleza. Más exactamente, se combinan aquí la reconstrucción consciente y la influencia no intencionada sobre el medio, resultado de lo cual es la asimilación social de la naturaleza y su transformación en medio ambiente humano. Aunque David Kidner se ha referido a esta tarea reconstructiva, no ha dejado de atribuirla a una «fantasía industrialista» y de señalar sus límites ante la «realidad ontológica» de la naturaleza (Kidner, 2000: 346). Más que comercialismo, sin embargo, es evolución: el hombre se apropia naturalmente de su medio y esa apropiación - quizá fatalmente - sólo puede intensificarse en el curso del tiempo. Por su parte, Tim Rogers ha apostado por una versión relacional del constructivismo que tome en consideración la interacción entre el hombre y el mundo natural, pero su trabajo trata de subrayar el estar-en-el-mundo del hombre, como medio para renovar la filosofía medioambiental, no de situar la transformación activa de la naturaleza por parte del hombre como elemento decisivo de su construcción social (Rogers, 2009).

En cualquier caso, es lógico que los teóricos verdes se opongan a esta conclusión, como se oponen a cualquier forma fuerte de constructivismo. Si el mundo natural es cada vez más humano, si ya no queda naturaleza propiamente dicha, sino una mezcla de naturaleza y artificio, el ecologismo se verá privado de objeto $\mathrm{y}$, con ello, de sentido. ¿Supone esto que un enfoque constructivista es inmoral, como se ha dicho? Depende de la función que se atribuya al científico social; pero parecería más inmoral ignorar la realidad en defensa de la moralidad. En todo caso, merece la pena ahondar en las consecuencias que comporta la aceptación de un construccionismo realista como el aquí defendido, lo que servirá, además, para poner de manifiesto su pertinencia. 


\section{Constructivismo y límites naturales}

El problema de los límites naturales a la actividad humana es un tema que atañe directamente a la disputa entre objetivismo y constructivismo. No sólo porque adoptar un punto de vista u otro proporcionará una valoración distinta del asunto, sino porque ésta habrá de manifestarse después en políticas de sostenibilidad que pueden divergir dramáticamente entre sí. Y aquí también, por añadidura, se ponen de relieve las limitaciones de un realismo sin construcción y de un constructivismo sin realidad.

No cabe duda de que el ecologismo político ha defendido siempre una aproximación objetivista a la delimitación de la actividad humana sobre el medio. De hecho, no se trata sólo de que los límites naturales puedan señalarse con rotundidad - la última pieza de carbón, el último pozo de agua-, sino que su existencia señala de paso las debilidades del enfoque constructivista cuando dejamos a un lado los juegos florales de la teoría del discurso: ¿no es inútil hablar de construcción social cuando se agotan los recursos que nos permiten sobrevivir?

Este énfasis en la existencia de límites naturales absolutos a la actividad humana ha formado parte de la identidad del movimiento verde desde su surgimiento, hasta el punto de que puede hablarse de una matriz malthusiana en el mismo, tal es la fidelidad con que reproducen las tesis del célebre economista inglés. Recordemos que, para éste, dado que el crecimiento de la población es geométrico y el de la producción de alimentos aritméticos, los recursos disponibles son un límite innegociable para la reproducción social (Malthus, 1999). Pero no fue así. La claridad de la fórmula es engañosa, porque excluye la posibilidad de mejora - humanamente inducidade la productividad natural. En sí misma, la naturaleza no es estática, sino dinámica; y la intervención humana intensifica ese dinamismo. La réplica que Marx diera a Malthus apunta precisamente en esta dirección antiesencialista. Marx niega que existan límites naturales absolutos impuestos al hombre; lo que hay son límites sociales a su actividad, que por definición son históricos y, por ello, transitorios. La naturaleza impone unos límites relativos, no absolutos. Y los límites naturales resultan ser límites sociales.

Premisa ésta cuya validez quedó demostrada durante el revival neomalthusiano provocado por la publicación, en 1968, de una obra pionera del movimiento verde: The Population Bomb. Su autor, Paul Ehrlich, alertaba en ella de la insostenibilidad alimentaria de las tendencias demográficas mundiales, dando con ello forma a un lenguaje de límites popularizado mundialmente por el Club de Roma cuatro años más tarde (cfr. Ehrlich, 1969). Su aviso no carecía de fundamento, pero terminó por convertirse en lo que Stewart Brand - veterano activista verde devejido heterodoxo - llama «profecías autoderrotistas». Y ello a causa del éxito de la revolución verde auspiciada por los trabajos de Norman Borlaug y la consiguiente multiplicación del rendimiento agrícola. Ni más ni menos que una intervención social que remueve un límite natural que parecía absoluto.

Puede así comprobarse cómo un constructivismo realista está mejor equipado que sus alternativas para explicar el carácter relativo de los límites naturales y la capacidad humana para trascenderlos mediante la reconstrucción social del medio natural. Son las interacciones socionaturales las que permiten esa constante redefinición. Así, la última pieza de carbón dará paso a otra fuente de energía; así ha sido siempre. La concepción objetivista de la naturaleza se basa en la idea de que los recursos naturales admiten una 
sola forma sostenible de uso, dada ya en el carácter mismo de las formaciones biofísicas; la concepción constructivista, en cambio, sostiene que hay muchas formas sociales de aprovechamiento sostenible de los recursos (Acselrad, 1999: 55). La propia noción de recurso tiene un fuerte acento constructivista.

Pero, ¿quiere esto decir que el medio no impone ningún límite a la actividad humana? No. Es evidente que la co-evolución recíproca experimentada entre una sociedad y una naturaleza que se transforman mutuamente puede operar tanto positiva como negativamente en relación a los límites naturales. Las sociedades pueden esquilmar sus recursos y desaparecer por ello. Pero el reconocimiento de que el medio natural establece límites al hombre es compatible con el señalamiento de que esos límites son relativos y no absolutos. Hablar de estos últimos supone avalar una concepción ahistórica de la sociedad y la naturaleza, contempladas como entidades inmóviles cuya interacción posee unos rasgos inamovibles. Y eso no es lo que indica la realidad histórica.

Hay que subrayar que no sólo cambia la sociedad, sino que la naturaleza lo hace también. Por un lado, el cambio evolutivo tiene lugar de manera gradual, al margen de la voluntad humana; por otro, las prácticas sociales producen consecuencias deseadas $y$ no deseadas sobre el medio natural, provocando en él ulteriores alteraciones. O sea:

«Decir que la escasez reside en la naturaleza y que existen los límites naturales, es ignorar en qué medida la escasez es socialmente producida y cómo los "límites" son una relación social dentro de la naturaleza (incluyendo la sociedad humana), más que una necesidad impuesta desde el exterior» (Harvey, 1996: 147).

Es verdad que la capacidad humana de transformación del medio se encuentra limitada por los propios elementos que el medio le proporciona, que el hombre puede manipular y recombinar, pero no soslayar. La transformación humana del mundo natural — su reproducción material y simbólica - no tiene lugar en el vacío, sino que está obligada a operar sobre la naturaleza preexistente que le sirve de materia prima. Sus resultados, por esa misma razón, reflejarán forzosamente ese mundo natural que es su punto de partida. Pero esa limitación - que podríamos llamar ontológica, porque el hombre no puede salirse de la realidad - no empece el reconocimiento de la formidable capacidad del hombre para trascender los límites que la naturaleza parecería imponerle.

En cualquier caso, una variante realista de constructivismo, asentada en la dimensión material de la relación socionatural, permite comprender que tanto los límites naturales vigentes en cada momento histórico, como los modos sociales de aprovechamiento del medio, traen causa de la interacción entre sociedad y naturaleza. Hablar de límites naturales relativos es reconocer la cualidad dinámica de la recíproca interdependencia socionatural y situar en el centro del análisis el proceso - material, cultural, simbólico- en que consiste la relación entre ambos. Porque las condiciones materiales de la vida social cambian a lo largo del tiempo. Y porque la sociedad transforma la naturaleza, pero en el curso de ese proceso la naturaleza también transforma la sociedad: sólo un enfoque constructivista permite reconocer y explicar esa realidad.

\section{Constructivismo y valor intrínseco de la naturaleza}

La amenaza que una perspectiva constructivista supone para los fundamentos filosóficos del ecologismo es aún más palpable cuando la ponemos en relación 
con el valor que quepa atribuir al mundo natural. Si la filosofía medioambiental ha defendido un principio con ahínco, es el valor independiente del mundo natural: independiente del juicio humano sobre él. Se sigue del mismo la proposición moral según la cual la naturaleza ha de ser preservada por su propio interés dada su condición de sujeto moral autónomo del hombre. Aunque el ecologismo es diverso, el rechazo del antropocentrismo constituye uno de los rasgos comunes de la mayor parte de las moralidades ecológicas.

Sucede que la afirmación del valor intrínseco del mundo natural depende de que éste exista en los términos en que el ecologismo suele describirlo: como una entidad independiente que el hombre no ha creado y de la que no podemos apropiarnos. En esta acepción, la naturaleza escapa a todas nuestras atribuciones de significado y afirma su autonomía tautológicamente: «Es tangible, segura, como una roca, estable, autoevidente, definible, real. En una palabra, es natural» (Price, 1998: 191). Pero si la naturaleza resultara ser - en mayor o menor medida - una construcción social, su valor independiente quedaría en entredicho:

Para esta concepción, es fundamental la asunción de que existe un modelo «correcto» de relaciones humanidad-naturaleza, independiente de cualquier perspectiva humana. De otro modo, la idea de transformar las actitudes de la gente en la dirección correcta no tendría sentido. Ocurre que la idea de semejante concepción independiente es ininteligible (Levy, 2004: 57).

Se apunta aquí hacia la objeción más habitual al valor intrínseco de la naturaleza, o sea, el hecho de que la misma idea de valor es una convención rabiosamente humana. Y se sugiere con ello cuál es uno de los problemas mayores del objetivismo verde: su ingenuidad epistemológica, sea ésta real o fingida. Porque no se pue- de ignorar el papel que juegan lenguaje y cultura en la percepción humana del mundo natural. Si se deja a un lado esta mediación, la afirmación del valor intrínseco se sostiene en el vacío.

Claro que, para el ecologismo, es el constructivismo epistemológico el que conduce a un callejón sin salida; más exactamente, a un idealismo lingüístico que termina por privarnos de todo fundamento para la protección del mundo natural. Si convenimos que lenguaje y cultura crean la realidad, nada puede tener valor si no es por medio de una atribución humana. Andrew Dobson es muy claro al respecto: «El ataque filosófico a la "naturaleza" equivale, así pues, a un ataque político a una sección importante - quizá la más importante- del movimiento ecologista» (Dobson, 1999: 1). La reducción de la naturaleza a mero constructo cultural es una amenaza directa para el programa moral del ecologismo, en la medida en que elimina las bases sobre las que otorgar un valor independiente al mundo natural.

No obstante, si bien el constructivismo ontológico es vulnerable a la réplica verde, no sucede lo mismo con el moderado y menos aún con la variante realista defendida en este trabajo. Porque reconocer la existencia de una naturaleza independiente del hombre que antecede al proceso de su apropiación social no implica aceptar un valor moral independiente para ella. Las historias natural y social convergen paulatinamente; no hay una naturaleza autónoma. Hubo alguna vez una naturaleza más o menos intacta, pero ya no existe, porque la historia humana la ha transformado; historia humana que es también, como tal, historia natural. Incluso aquellas partes del planeta aparentemente vírgenes lo son en virtud de una omisión humana. ¿Quiere decirse que no existen razones para proteger el mundo natural o defender ciertas políti- 
cas de sostenibilidad? Nada de eso; pero es conveniente ser realista acerca del carácter de aquello que decidimos proteger y acerca de las fuentes de su valor.

\section{Para una mejor comprensión} de las relaciones socionaturales

Ya se ha señalado que las insuficiencias presentadas por las formas fuertes de realismo y constructivismo han desembocado en una suerte de consenso práctico en torno a una síntesis moderada de ambos: realidad del objeto, construcción del conocimiento. Sin embargo, también se ha apuntado que el constructivismo resultante no da cuenta de la dimensión directamente material de la construcción social de la naturaleza, razón por la cual se sostiene aquí la necesidad de abrir paso a un constructivismo cualificado, basado en la interacción socionatural. Sólo a partir del mismo parece posible comprender la auténtica realidad de las relaciones sociedad-naturaleza, como premisa para su adecuada articulación política a través del principio de sostenibilidad.

Por un lado, las variantes fuertes de realismo y constructivismo privilegian uno de los dos polos de la relación socionatural, hasta anular al otro: la naturaleza será eminentemente natural o enteramente social, pero su mutua interacción no recibirá la atención que merece. Por otro, la corrección moderada de estas tesis, que adopta la forma de un constructivismo epistemológico, sí tiene en cuenta esa interacción, pero postula una relación atenuada entre sociedad y naturaleza al no tomar en consideración la dimensión material de la construcción social de la naturaleza. De ahí la pertinencia de avanzar hacia un constructivismo realista o cualificado.

Es conveniente repetir que la realidad objetiva del mundo natural no es puesta aquí en cuestión. Para que pueda tener lugar la producción social de la na- turaleza es necesario que preexista a ésta una realidad natural: no se puede construir sin materiales. En consecuencia, la reconstrucción subsiguiente reflejará la índole de esa materia prima; inevitablemente. El mundo natural no determina el proceso de su apropiación social, pero sí condiciona su desarrollo: las formas históricas de la interacción material, cultural y simbólica manifestadas en el curso de ese proceso serán un reflejo de la concreta realidad a partir de la cual se construye. Sólo podemos dar forma al mundo trabajando sobre el mundo mismo. Tiene razón Ted Benton cuando dice que:

«ni importa cuán "profundo" lleguemos en la estructura de los materiales y seres con los que trabajamos, sigue siendo el caso que las transformaciones [hechas por el hombre en el mundo natural] presuponen constancia en la estructura y poderes causales en un nivel estructural profundo, y están limitadas por la naturaleza de esa estructura de nivel profundo» (Benton, 1992: 66).

Esta enmienda al constructivismo epistemológico no niega la independencia de la naturaleza profunda, por decirlo en los términos de Kate Soper (1995). Aunque podemos alterar sus estructuras en medida cada vez mayor, no podemos reemplazarlas. No está tan claro, sin embargo, que esta circunstancia posea el significado que Benton querría darle, puesto que la existencia de este límite último para nada empece una más que probada capacidad humana para transformar - también profundamente- la naturaleza existente.

Además, ese mundo natural que precede al hombre no es sólo una precondición de su trabajo, sino también, enseguida, un resultado simultáneo del proceso de su interacción: la naturaleza cambia al compás del hombre y viceversa. En otras palabras, si la naturaleza como realidad objetiva constituye forzosamente el presupuesto para su aprehensión social, no 
es menos cierto que ese mundo físico una vez transformado ya es parte del contexto del que depende la construcción que cada sociedad hace de la naturaleza. En preclara formulación del malogrado Nikolái Bujarin:

El proceso de producción social es una adaptación de la sociedad humana a la naturaleza externa. Pero es un proceso activo. Cuando una especie animal se adapta a la naturaleza, se somete, en realidad, a la acción constante de su medio ambiente. Cuando la sociedad humana se adapta a su medio, lo adapta a su vez a ella, y no es sólo objeto de la acción de la naturaleza, sino que a su vez y simultáneamente transforma a la naturaleza en objeto de trabajo humano (Bujarin, 1972: 200).

Se trata de una interacción que opera en múltiples niveles y direcciones. Transformamos una realidad que a su vez nos transforma, pero el producto de ese proceso modifica la realidad sobre la que actuamos, y así sucesivamente. Dado que esta intervención transformadora del entorno se lleva a cabo sobre una realidad preexistente, más que de construcción convendría acaso hablar de reconstrucción del mundo natural.

Nunca cerrado, el proceso de apropiación humana de la naturaleza presenta dos dimensiones ligadas entre sí: la material y la cultural. Hay una relación directa entre los procesos materiales (la extracción de carbón de una mina, la manipulación de fibra óptica, la recombinación del ADN) y los procesos culturales (el estudio del medio para desvelar sus leyes, la atribución de significado a esas prácticas, su justificación ante la comunidad); el resultado de esa relación determina la forma que en cada momento histórico adopta la interacción sociedad-naturaleza. En palabras de Michael Redclift: «Somos material y simbólicamente creativos $\mathrm{y}$ destructivos; remodelamos nuestros entornos física y cognitivamente» (Redclift, 1999: 67). A su vez, esa remodelación in- cide sobre la cultura de una sociedad, sobre sus costumbres, sobre su percepción de la realidad y su actitud hacia el futuro. Son procesos mutuamente contingentes, que se constituyen de forma conjunta, de manera que su separación conceptual no oculta la imposibilidad de su completa separación práctica.

Hay, por tanto, un propósito antirreduccionista en la defensa de un construccionismo cualificado. Si la construcción social de lo natural comprende, en el contexto de la co-evolución de sociedad y naturaleza, tanto los procesos materiales como los culturales, entonces no es posible hacer derivar unos de otros, ni privilegiar una sola parte — sea la cultural o la material- del proceso global de producción social de la naturaleza en el intento de explicar su complejidad. Poner el énfasis sobre la interacción sociedad-naturaleza es así un modo de reconocer la complejidad de unas relaciones que no pueden reducirse a términos exclusivamente culturalistas ni materialistas. Es necesario más bien combinar los aspectos materiales, culturales y simbólicos de esa interacción, porque todos ellos conforman el más amplio proceso de construcción social de la naturaleza mediante el cual el hombre - guste o no- se apropia del entorno, humanizando la naturaleza hasta convertirla en $s u$ medio ambiente ${ }^{1}$.

\section{De la naturaleza al medio ambiente}

Ya se ha visto que la naturaleza es parte de la historia humana, porque sus formas se han desarrollado junto a las formas sociales. Y dado que la especie humana ha evolucionado mediante su diferenciación de la naturaleza, sin dejar de pertenecer a ella, su adaptación al entorno ha consistido primordialmente en su transformación a través del trabajo. Es por eso que podemos hablar de un proceso de construcción social de la naturaleza; proceso que es tanto material como simbólico. Su cul- 
minación no es sino la transformación de la naturaleza en el medio ambiente del hombre.

Desde este punto de vista, la sociedad es un desarrollo histórico dentro de la naturaleza, que paradójicamente aleja al hombre de ella. Ahora bien, es importante tener presente que esta separación va más allá de la simple diferenciación, porque simultáneamente adopta la forma de una apropiación del entorno. Ésta es, en realidad, otra paradoja: la separación humana de la naturaleza se realiza a través de una interacción cada vez más intensa con el medio. Pero, ¿no es una paradoja sólo aparente? ¿Acaso no es la separación cognitiva y simbólica un presupuesto necesario de las relaciones socionaturales? Por decirlo con Niklas Luhmann, estamos ante una oposición binaria por medio de la cual la civilización emerge como contraconcepto frente a la naturaleza (Luhmann, 1989: 2). Y cuanto más firmemente está asentada en nuestra imaginación esa separación, cuanto mayor es el distanciamiento simbólico, más intensa es en la práctica la interacción material entre sociedad y naturaleza. Y más difícil es también fijar la línea que los separa:

«Así, no hay una única forma en la que nosotros, como seres humanos, nos relacionemos con la naturaleza externa. La aceptación del carácter complejo e interactivo del cambio social y medioambiental implica que las distinciones simples entre lo "social" y lo "natural" pronto serán insostenibles» (Redclift, 1999: 68).

Pues bien, la transformación de la naturaleza en medio ambiente humano pone un fin, en forma de bucle, a ese proceso histórico: naturaleza y sociedad vuelven a reunirse, pero esta vez bajo el signo de lo social. La diferenciación entre sociedad y naturaleza termina por invertir el punto de partida: si al principio hubo una naturaleza indiferenciada, ahora vivimos en un me- dio ambiente indiferenciado. En este contexto, una concepción de la naturaleza como la defendida a menudo por el ecologismo se encuentra de bruces con la realidad. Porque sólo sustrayendo la dimensión sociohistórica de la naturaleza puede incurrirse en la idealización de un mundo natural presentado como ahistórico y autónomo, idealización que sólo puede presentarse por medio del sentimentalismo: «Y aún tras estos miedos y esperanzas obvios e inmediatos reside un profundo significado, que sólo conoce la montaña misma. Sólo la montaña ha vivido lo suficiente para escuchar objetivamente el aullido de un lobo» (Leopold, 1987: 129).

Sólo sobre estos fundamentos parece posible plantear una reformulación conceptual que diferencie debidamente entre naturaleza y medio ambiente. Por más que ambos términos se empleen frecuentemente como sinónimos en el debate público sobre la crisis ecológica, es conveniente diferenciarlos rigurosamente, a fin de poder debatir, también rigurosamente, sobre la clase de sostenibilidad que queremos. Naturaleza y medio ambiente no son la misma cosa porque el medio ambiente es, de hecho, aquello en que se ha convertido la naturaleza. En otras palabras: el medio ambiente es el producto de la historia social de la naturaleza, de su incorporación a la historia humana, de su transformación por el trabajo. Mediante esa intervención material sostenida en el entorno, la naturaleza se humaniza y lo natural pasa a ser social. Encontramos trazos de este realismo en la idea de paisaje defendida por Martin Drenthen, para quien en aquél son visibles los restos del diálogo hombre-naturaleza, por medio del cual «cultura y naturaleza se mezclan más o menos orgánicamente en un todo significativo» (Drenthen, 2009). Es decir, que la naturaleza se subsume en el medio ambiente.

No obstante, eso no quiere decir que todo lo natural se convierta en artificio. 
Primero, porque, desde cierto punto de vista, todo sigue siendo natural en cualquier caso. Y segundo, sobre todo, porque existen distintos grados de humanización del mundo natural; la apropiación social no siempre es total. Hay espacios, territorios, que han sido intervenidos en menor medida, y que por esa razón conservan una mayor semejanza con nuestro ideal de naturaleza - y digo ideal porque una bacteria es tan natural como un bosque de hayas. Su conservación, en todo caso, responde a decisiones sociales en origen y sirven al cumplimiento de finalidades asimismo sociales, ya se definan en términos de equilibrio medioambiental, respeto a ciertas formas naturales por razones morales, o satisfacción estética o espiritual del propio hombre. Pero eso no es ya, propiamente, naturaleza, sino medio ambiente.

Pese a ello, el concepto de medio ambiente puede seguir resultando confuso si no se explicita su oposición al concepto de naturaleza. Y es que hablamos de medio ambiente porque ya no podemos hablar de naturaleza: porque ésta ha desaparecido al transformarse en aquél. La sola distinción entre uno y otra es, por eso, incongruente, ya que el medio ambiente es lo que era la naturaleza; una sola cosa y no dos distintas. Hablar de naturaleza en un sentido arcádico es invocar una abstracción, porque semejante naturaleza sólo puede existir fuera de la historia; el medio ambiente es la naturaleza después de la historia. Sustituir un término por otro, o distinguirlos adecuadamente, no es otra cosa que sujetarse al principio de realidad a la hora de contemplar las relaciones de la sociedad con su entorno. El medio ambiente es lo que la naturaleza ha llegado a ser a través de su relación histórica con la sociedad.

\section{Conclusión}

La aportación del pensamiento constructivista al estudio de la naturaleza ha sido rechazada desde el principio por la mayoría de los teóricos verdes, por razones que oscilan entre la indignación espontánea y el temor fundado. Indignación ante la sola idea de que pueda negarse ontológicamente la existencia del mundo natural y temor ante la posibilidad de que el desarrollo de las tesis constructivistas pueda privar al ecologismo político de su razón de ser. Esto último se refleja en el argumento de que el constructivismo posee un déficit moral en lo que toca a la defensa del mundo natural, de manera que una sociedad sostenible no parece poder basarse en una concepción constructivista de la naturaleza.

Sin embargo, muchos de estos argumentos apuntan hacia las versiones radicales u ontológicas de constructivismo, por lo demás difíciles de encontrar en la literatura. El problema es que no resulta tan fácil poner en entredicho a la versión moderada o epistemológica de constructivismo, alrededor de la cual, por ello, ha terminado por forjarse un cierto consenso. Se admite así que existe una naturaleza cuyo conocimiento por parte del hombre está socialmente mediado: realismo del objeto y constructivismo del conocimiento. Esto no satisface a quienes defienden una idea arcádica de la naturaleza, asociada a una aproximación espiritual del hombre a la misma, pero permite al menos conservar la ilusión de que existe un mundo natural esencial, ahistórico y universal fuera de la sociedad. Pero se trata, sí, de una ilusión.

Y lo es porque esta distinción binaria entre un constructivismo moderado y otro radical es insuficiente para explicar de una manera realista las relaciones del hombre con su entorno. No hay una naturaleza exterior y un conocimiento interior a la sociedad, sino que sociedad y naturaleza se relacionan intensamente desde el principio de los tiempos mediante el trabajo humano de adaptación al entorno, 
adaptación que toma la forma de una apropiación y humanización de la naturaleza. Se hace necesario, por ello, imprimir un giro realista al constructivismo medioambiental, a fin de superar la dicotomía entre objeto y conocimiento mediante la incorporación de la dimensión material de la relación socionatural. No sólo el concepto de naturaleza es una construcción social; la naturaleza misma también lo es. Sociedad y naturaleza han co-evolucionado a lo largo de un proceso relacional que supone primeramente la apropiación social del medio. La creciente capacidad del hombre para humanizar la naturaleza, cuyo último episodio es la creación de organismos sintéticos en el laboratorio, atestiguan la falta de realismo de aquellos enfoques que insisten en defender una naturaleza separada e independiente del hombre.

En realidad, la naturaleza ya no existe. No existe, porque la culminación de ese proceso histórico de co-evolución y recíproca interpenetración socionatural es la transformación de la naturaleza en medio ambiente humano. El medio ambiente es aquello que la naturaleza ha venido a ser. Y los problemas conceptuales derivan, en su mayor parte, de la obstinación con que seguimos llamando naturaleza a cualquier escenario pastoril. Lo que tenemos delante no es ninguna esencia atemporal, sino el producto de las transformaciones humanas del medio. Lo que se opone al concepto de medio ambiente es, entonces, la idea verde de la naturaleza: un orden idealizado y definido por su independencia. Pero esa independencia es una ficción, una apariencia: naturaleza y sociedad son interdependientes. Mientras que el concepto de naturaleza remite a una realidad autosuficiente y cerrada, sólo posible antes de la historia, el de medio ambiente se refiere al mundo constituido relacionalmente, a un mundo natural que interactúa con la sociedad y por eso se transforma. La dicotomía naturaleza-sociedad se disuelve en medio ambiente.

¿Supone esto incurrir en alguna clase de inmoralidad, en la medida en que un constructivismo realista haría más difícil la defensa del principio de sostenibilidad? No parece ser el caso. Sobre todo, porque este planteamiento no es el más correcto. Si el constructivismo realista dijera la verdad sobre las relaciones socionaturales, o cuando menos hiciera una propuesta de verdad digna de ser tenida en cuenta, ¿habría que ignorarla, porque sus conclusiones no encajan con el programa de quienes defienden una determinada concepción del mundo natural y una versión de la sostenibilidad entre las muchas posibles? Dicho de otra manera, ¿hay que sacrificar la ciencia a la moralidad?

En realidad, una versión material del constructivismo no supone ningún obstáculo para la consecución de la sostenibilidad, sino que, más al contrario, debería servir a una correcta comprensión de la misma. Porque difícilmente tendría sentido defender una forma de sostenibilidad que no reflejase la realidad de nuestra interacción con el mundo natural. No hay una única forma posible de sostenibilidad, sino distintas variantes de la misma; y elegir entre ellas, si es que esa elección explícita es posible, exige que comprendamos antes rectamente de qué hablamos cuando hablamos de nuestras relaciones con la naturaleza. Que la realidad pueda desagradarnos no es razón suficiente para dejar de contemplarla.

\section{BIBLIOGRAFÍA}

ACSELRAD, Henri (1999): «Sustainability and Territory: Meaningful Practices and Material Transformations», en Becker et al. (eds.), Sustainability 
and the Social Sciences. A cross-disciplinary approach to integrating environmental considerations into theoretical reorientation, Londres: Zed Books, pp. 37-58.

Benton, Ted (1992): «Ecology, Socialism and the Mastery of Nature: A Reply to Reiner Grundmann», en New Left Review, n. ${ }^{\circ}$ 194, pp. 55-74.

Benton, Ted (1994): «Biology and Social Theory in the Environmental Debate», en M. REDCLIFT y T. BENTON (eds.), Social Theory and the Global Environment, Londres: Routledge, pp. $28-50$.

BENTON, Ted (2000): «Critical Realism and the Environment», texto de la conferencia ofrecida en el Oxford Centre for the Ethics, Society and the Environment, del Mansfield College, Oxford, 15 de noviembre.

Berger, Peter y Luckmann, Thomas (1984), La construcción social de la realidad, Madrid: Amorrortu-Murguía.

BHASKAR, Roy (1989): The Possibility of Naturalism, Londres: Harvester Wheatsheaf.

BLÜHDORN, Ingolfur y WELSH, Ian (2007): «Eco-politics beyond the Paradigm of Sustainability: A Conceptual Framework and Research Agenda», Environmental Politics, 16 (2), pp. 185-205.

Bujarin, Nicolai I. (1972), Teoría del materialismo histórico, Madrid: Siglo XXI.

Burnigham, Kate y CoOper, Geoff (1999): «Being Constructive: Social Constructionism and the Environment», Sociology, 33 (2), pp. 297-316.

Castro Nogueira, Luis; Castro NoGUEIRA, Miguel Ángel y Morales NAVARro, Julián (2005): Metodología de las ciencias sociales. Una introducción crítica, Madrid: Tecnos.

Dickens, Peter (1996): Reconstructing Nature. Alienation, Emancipation and the Division of Labour, Londres: Routledge.

Dobson, Andrew (1999): «Nature: only a social construct?», manuscrito, versión provisional.

DrEnthen, Martin (2009): «Ecological Restoration and Place Attachment: Emplacing Non-Places?», Environmental Values, 18, pp. 285-312.

DunlaP, Riley y CATTON, William R. (1994): «Struggling with Human Exemptionalism: The Rise, Decline and Revitalization of Environmental Sociology», American Sociologist, primavera, pp. 5-30.

EDER, Klaus (1996): «The Institutionalisation of Environmentalism: Ecological Discourse and the Second Transformation of the Public Sphere», en S. LASH, B. SzERSZYNSKi y B. WynNE (eds.), Risk, Environment and Modernity. Towards a New Ecology, Londres: Sage, pp. 203-223.

Ehrlich, Paul R. (1969), The Population Bomb, New York: Sierra Club.

KIDNER, David W. (2000), «Fabricating Nature: A Critique of the Social Construction of Nature», en Environmental Ethics, vol. 22, n. ${ }^{\circ}$ 4, pp. 339-358.

HaRveY, David (1996): Justice, Nature \& the Geography of Difference, Londres: Blackwell.

LEASE, Gary (1995): «Nature under fire», en M. E. Soulé y G. LeAse (eds.), Reinventing Nature, Washintong DC: Island Press.

Leopold, Aldo (1987), A Sand County Almanac. And Sketches Here and There, Oxford: Oxford University Press.

LEVY, Yoram (2004): «The end of environmentalism (as we know it)», en Y. LEVY y M. WISSENBURG (eds.), $L i$ beral Democracy and Environmentalism. The End of Environmentalism?, Londres: Routledge, pp. 48-59.

LUHMANN, Niklas (1989): Ecological Communication, Cambridge: Polity. 
Macnaghten, Phil y Urry, John (1998): Contested Natures, Londres: Sage.

Malthus, Robert (1999): An Essay on the Principle of Population, Nueva York: Oxford University Press.

MARTELL, Luke (1994): Ecology and Society. An introduction, Cambridge: Polity Press.

MarX, Karl (1978): El Capital. Crítica de la Economía Política. 3 Vols., México: FCE.

MORIARTY, Paul Veatch (2007): «Nature Naturalized: A Darwinian Defense of the Nature/Culture Distinction», en Environmental Ethics, vol. 29, otoño, pp. 227-246.

MoscovicI, Serge (1975), Sociedad contra natura, México DF: Siglo XXI.

Plumwood, Valerie (2005): «Toward a Progressive Naturalism», en T. HEYD (ed.), Recognizing the Autonomy of Nature. Theory and Practice, New York: Columbia University Press, pp. 25-53.

PRICE, Jennifer (1998): «Looking for Nature at the Mall: A Field Guide to the Nature Company», en W. CRONON (ed.), Uncommon Ground. Rethinking the Human Place in Nature, Nueva
York: W. W. Norton \& Company, pp. 186-203.

REDCLIFT, Michael (1999): «Sustainability and Sociology: Northern Preoccupations», en BECKER et al. (eds.), Sustainability and the Social Sciences. A cross-disciplinary approach to integrating environmental considerations into theoretical reorientation, Londres: Zed Books, pp. 59-73.

Rogers, Tim B. (2009): «Nature of the Third Kind»: Toward an Explicitly Relational Constructionism», Environmental Ethics, vol. 31, invierno, pp. 393-412.

SAARIKOSKI, Heli (2007): «Objectivity and the Environment-Epistemic Value of Biases», Environmental Politics, 16 (3), pp. 488-498.

SiSMONDO, Sergio (1993): «Some social constructions», Social Studies of Science, 23, pp. 515-553.

SMITH, Mick (1999): «To Speak of Trees: Social Constructivism, Environmental Values, and the Future of Deep Ecology», Environmental Ethics, vol. 21, pp. 359-376.

Soper, Kate (1995): What is Nature?, Oxford: Blackwell.
${ }^{1}$ La sobredeterminación material de la apropiación humana de la naturaleza, coherente con las premisas de su materialismo, es el único problema que plantea el brillante concepto empleado por el Marx maduro para explicar las relaciones socionaturales: el concepto de metabolismo (cfr. Karl Marx, 1978: 130 ss.). Que designa el intercambio material que, por medio del trabajo, tiene lugar de forma constante entre sociedad y naturaleza - un fenómeno transhistórico, por más que sus manifestaciones concretas tengan, ciertamente, lugar en la historia-. Hay que recordar cómo, para Marx, la historia se concibe como la progresiva humanización de la naturaleza, junto a la que tiene también lugar la naturalización de la humanidad, en el sentido de realización del hombre como especie. El metabolismo sociedad-naturaleza a que el trabajo da forma es así «un proceso social de reproducción» (Bujarin, 1972: 201). Es un proceso dinámico, de pérdida y restablecimiento constantes del equilibrio de sociedad y naturaleza. Sin embargo, la dimensión cultural y simbólica del proceso de apropiación de la naturaleza no serían más que la expresión superestructural de la estructura material que está en su base y que constituye su sustento; ausente ésta, las ideas y símbolos que genera también se desvanecen: sino del epifenómeno. 